CLINICAL STUDY

\title{
Seasonality of month of birth of patients with Graves' and Hashimoto's diseases differ from that in the general population
}

\author{
Gerasimos E Krassas, Konstantinos Tziomalos ${ }^{1}$, Nikolaos Pontikides, Hadas Lewy ${ }^{2}$ and Zvi Laron ${ }^{2}$ \\ Department of Endocrinology, Diabetes and Metabolism, Panagia General Hospital, N Plastira 22, Thessaloniki 55132, Greece, ${ }^{1}$ Second Propedeutic \\ Department of Internal Medicine, Hippokration Hospital, Aristotle University of Thessaloniki, Thessaloniki, Greece and ${ }^{2}$ Endocrinology and Diabetes \\ Research Unit, Sackler Faculty of Medicine, Schneider Children's Medical Center of Israel, Tel Aviv University, Tel Aviv, Israel \\ (Correspondence should be addressed to GE Krassas; Email: krassas@the.forthnet.gr)
}

\begin{abstract}
Objective: We aimed to test the viral hypothesis in the pathogenesis of autoimmune thyroid disease (AITD).

Design: We determined the pattern of month of birth (MOB) distribution in patients with AITD and in the general population and searched for differences between them.

Methods: A total of 1023 patients were included in this study; 359 patients had Graves' hyperthyroidism $(\mathrm{GrH})$ and 664 had Hashimoto's hypothyroidism $(\mathrm{HH})$. We divided the patients with $\mathrm{HH}$ into three subgroups according to their thyroid peroxidase (TPO) antibody titers at diagnosis: low levels $(<500 \mathrm{IU} / \mathrm{ml})$, high levels $(500-1000 \mathrm{IU} / \mathrm{ml})$, and extremely high levels $(>1000 \mathrm{IU} / \mathrm{ml})$. We used cosinor analysis to analyze the data.

Results: Overall, patients with GrH and HH had a different pattern of MOB distribution when compared with the general population and between groups. Furthermore, among both patients with GrH and $\mathrm{HH}$, both genders had a different pattern of MOB distribution when compared with the general population and this pattern was also different between genders. Finally, only women with extremely high titers of TPO antibodies at diagnosis and men with low or extremely high TPO antibody levels showed rhythmicity in MOB, with a pattern of MOB distribution different from that in controls. Conclusions: The different MOB seasonality in both $\mathrm{GrH}$ and $\mathrm{HH}$ points towards a similar maybe even common etiology with type 1 diabetes mellitus and multiple sclerosis, namely a seasonal viral infection as the initial trigger in the perinatal period, the clinical disease resulting from further specific damage over time.
\end{abstract}

European Journal of Endocrinology 156 631-636

\section{Introduction}

Graves' disease (GrD) and Hashimoto's thyroiditis (HT) are common disorders with an autoimmune origin and are also therefore alluded to as autoimmune thyroid diseases (AITD; $(1,2)$ ). Like other organ-specific autoimmune endocrinopathies, they have a multifactorial but different etiology (3). It has been calculated that $21 \%$ of the cause to develop $\mathrm{GrD}$ can be attributed to environmental factors $(1,3)$. This is less documented for HT (4). Among the environmental factors, infections especially viruses have been mentioned (1) but so far only an association between congenital rubella infection and hyperthyroidism has been documented (5). Evidence for a link between viral infection and the autoimmune process has been repeatedly shown in type 1 diabetes (T1D) mellitus (6-11) and multiple sclerosis (MS; (12)). Since there is a high degree of association between T1D with both GrD and HT (13) and possibly MS (14), one can assume that autoimmune diseases have despite different antigens and antibodies a common trigger in the initiation of the autoimmune process, probably viral infections in the perinatal period. Viral infections have been recognized to act in $\mathrm{T} 1 \mathrm{D}$ as the last insult leading to the conversion of the subclinical to clinical disease thus showing a higher incidence of clinical diagnosis during seasons of endemic viral outbreaks, usually late autumn and winter $(8,15,16)$.

Seasonal variations in the frequency of AITD are also known to support the viral hypothesis (17-20). Considering the strong link between T1D and AITD (13) and the finding that children and young adults who subsequently developed T1D had a different seasonality of month of birth (MOB) from that found in the general populations (21-23), we analyzed the seasonality of MOB in a large cohort of patients with Graves' hyperthyroidism $(\mathrm{GrH})$ and Hashimoto hypothyroidism $(\mathrm{HH})$. This article presents the results of this analysis.

\section{Subjects and methods}

We studied all patients who were first diagnosed with AITD from January 2003 up to November 2005 as well as all 
patients who were being followed up at the Endocrine Outpatient Department of Panagia General Hospital, in Thessaloniki, Greece. The study population was subdivided according to the diagnosis of patients with $\mathrm{GrH}$ and $\mathrm{HH}$.

A total of 1023 patients were included in this study; their characteristics are shown in Table 1. Male sex was more prevalent among patients with $\mathrm{GrH}$ than among those with $\mathrm{HH}(P=0.015)$. Patients with $\mathrm{GrH}$ were significantly older at diagnosis when compared with patients with $\mathrm{HH}(P=0.003)$. Age at diagnosis, overall and in $\mathrm{GrH}$ and $\mathrm{HH}$ separately, did not differ significantly between men and women.

$\mathrm{MOB}$, thyroid stimulating hormone (TSH), and free thyroxine $\left(\mathrm{FT}_{4}\right)$ were recorded in all patients. Titers of antibodies against thyroid peroxidase (TPO) were determined in patients with $\mathrm{HH}$ at their initial visit. Patients with $\mathrm{GrH}$ had elevated levels of $\mathrm{FT}_{4}$ and suppressed TSH, while patients with $\mathrm{HH}$ had elevated TSH levels $(>10 \mathrm{mU} / \mathrm{l}$, normal range $=0.4-4.0 \mathrm{mU} / \mathrm{l})$, decreased levels of $\mathrm{FT}_{4}$ (normal range $=7.0-18.0 \mathrm{pg} / \mathrm{ml}$ ), and positive TPO antibodies (normal range $<50 \mathrm{IU} / \mathrm{ml}$ ). Most of the latter had a thyroid ultrasound scan, which was consisted with the diagnosis of autoimmune thyroiditis. The diagnosis of $\mathrm{GrH}$ was based, except for high levels of $\mathrm{FT}_{4}$ and suppressed TSH, on one or more of the following: various degrees of diffuse goiter (clinically or by ultrasound scan), ophthalmopathy or elevated levels of thyroid receptor antibodies (TRAbs). The serum concentrations of $\mathrm{FT}_{4}$ and TSH were measured by standard, commercial RIA kits (DiaSorin, 13040, Saluggia (VC), Italy). TPO antibody titers were determined by commercial RIA kit (Brahms, Henningsdorf, Germany).

\section{Statistical analysis}

We analyzed the data using cosinor analysis (24). Cosine approximation $Y_{\mathrm{i}}$ (monthly number of births)= $M+A \times \operatorname{COS}\left(\omega t_{\mathrm{i}}+\phi\right)$ yield the following parameters: $\mathrm{M}$ is the time series mean (Midline Estimating Statistic Of Rhythm), $A$ is the amplitude (one-half of the peak to trough variation), and acrophase $(\phi)$ is the peak time of the calculated rhythm. $T_{\mathrm{i}}$, the time in months; $(\omega t)$, the period of the rhythm (2D Table curve, Jandel Scientific, San Rafael, CA, USA). The data were compared with the pattern of total live births during 2003-2004 in Thessaloniki, Greece $(n=37$ 119). Information was

Table 1 Demographic characteristics of the patients.

\begin{tabular}{lccc}
\hline & $\begin{array}{c}\text { Overall } \\
(n=1023)\end{array}$ & $\begin{array}{c}\text { GrH } \\
(n=359)\end{array}$ & $\begin{array}{c}\text { HH } \\
(n=664)\end{array}$ \\
\hline $\begin{array}{l}\text { Mean age at } \\
\text { diagnosis } \pm\end{array}$ & $42.4 \pm 14.4$ & $44.5 \pm 14.1$ & $41.3 \pm 14.5$ \\
$\begin{array}{c}\text { S.D. (years) } \\
\text { Gender (\%) }\end{array}$ & & & \\
Males & 17.9 & 22.0 & \\
Females & 82.1 & 78.0 & 15.7 \\
\hline
\end{tabular}

$\mathrm{GrH}$, Graves' hyperthyroidism; HH, Hashimoto's hypothyroidism. obtained from the national registry of Central Macedonia, Greece.

\section{Results}

The overall results are summarized in Table 2. The rhythmic patterns of the seasonality of MOB are graphically illustrated in Figs 1 and 2 .

In the general population, in both males and females, the highest incidence of births was noticed during summer (Fig. 1; $P<0.01$ and $P<0.05$ respectively). In contrast, both genders with $\mathrm{GrH}$ had a different pattern of MOB distribution when compared with the general population, which also differed between the genders. More specifically, more males with $\mathrm{GrH}$ had been born during winter $(P<0.01)$, whereas females showed two peaks in the distribution of births, one in spring and one in autumn $(P<0.01)$.

Figure 2 illustrates the comparison between the distribution of MOB in patients with $\mathrm{HH}$ and the general population. It is clear that the pattern of both genders with $\mathrm{HH}$ differs from that of the general population and also that the pattern of MOB differs between the two genders. The males have two peaks, one in summer and one in winter $(P<0.01)$, whereas the females have only one in winter $(P<0.01)$.

To find out whether the pattern of MOB in patients with HH differs with the serum TPO antibody titers, we divided the patients with $\mathrm{HH}$ arbitrarily into three subgroups according to their TPO antibody titers at diagnosis: low levels $(<500 \mathrm{IU} / \mathrm{ml})$, high levels (500-1000 IU/ml), and extremely high levels (> $1000 \mathrm{IU} / \mathrm{ml}$; Fig. 2). In women, the only group that showed rhythmicity was the group with extremely high titers $(P<0.01)$ with a pattern different from that of controls but identical with that of the entire female population with $\mathrm{HH}$. In contrast, women with low or high levels showed no rhythmicity. In men, both groups with low $(P<0.01)$ and extremely high TPO antibody levels $(P<0.01)$ showed rhythmicity in MOB. The pattern of MOB distribution was different between these two subgroups as well as from the controls. In contrast, men with high levels showed no rhythmicity.

\section{Discussion}

To the best of our knowledge, the fact that the seasonal and monthly pattern of birth of patients with AITD differs from that of the general population has not been reported so far. Our study shows an abnormal seasonality of birth in a large independent Greek population with AITD, both $\mathrm{GrH}$ and $\mathrm{HH}$. This is unlikely to be due to chance, and it is difficult to conceive of a bias that might account for the results. Of note, no reports are available from the local Department of Health stating that the prevalence of specific or 


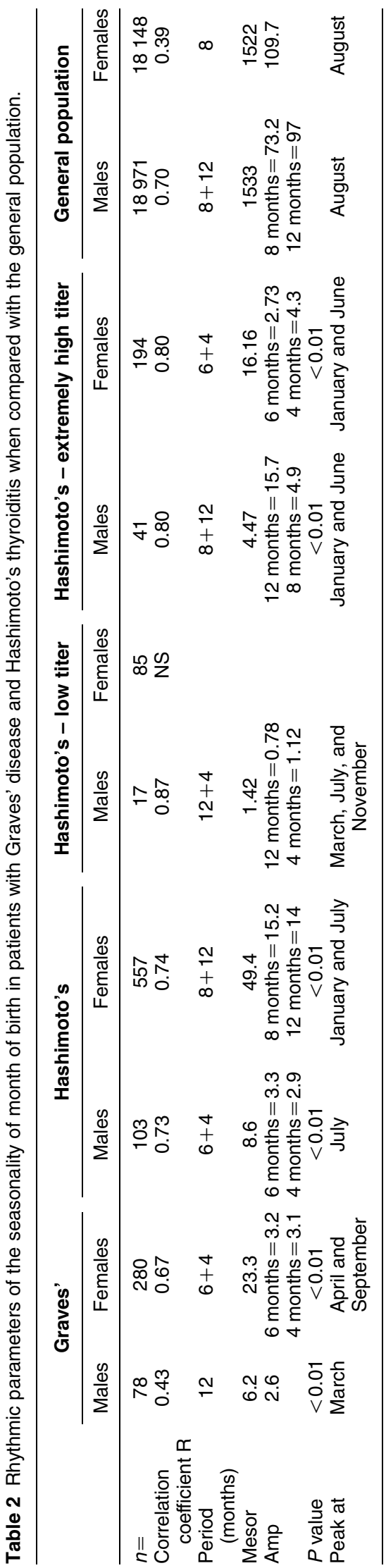

general viral infections in the area was different from usual 40-45 years ago, which is the age of most of our patients today.

Several important conclusions can be drawn from our observations. Whereas both genders in the general population had a rhythmic seasonal pattern with an excess of births in the summer and early autumn months, the pattern of MOB distribution in both genders with $\mathrm{HH}$ differs from that of the general population. In the general population, in both males and females, the highest incidence of births was noticed during summer; whereas male patients with $\mathrm{HH}$ had two peaks, one in summer and one in winter, and the females had only one in winter.

Regarding patients with $\mathrm{GrH}$, both genders had a different pattern when compared with the general population, with an additional difference between them (the peak in the males being in winter and the females having two peaks, in spring and autumn). The findings of two periods of excess births may suggest the existence of more than one subpopulation in the groups analyzed. This may be due to genetic or environmental factors.

In addition, we observed variation in MOB seasonality in patients who had extremely high TPO titers when compared with those with low titers. Of note is that antibody measurements were performed only at the initial visit. In addition, it has to be mentioned that the term autoimmune thyroiditis encompasses several different entities whose interrelationships remain unclear. This supports the heterogeneous nature of the disease.

Our findings are in line with observations for T1D mellitus (T1DM) that the clinical onset follows an infection with an increased incidence in autumn and winter, i.e., during the months of the yearly virus epidemics (15). Further epidemiological studies showed that patients who subsequently developed T1DM (21-23) or MS (25) had a different seasonality pattern in MOB than the general population, the peak prevalence being in the spring and summer months. These findings were interpreted as support of the 'viral hypothesis' assuming that the viral infections in autumn and winter trigger the autoimmune process in genetically susceptible fetuses conceived during those periods of the year. Graves' disease and Hashimoto's thyroiditis are autoimmune diseases (26) and the different pattern of MOB found in these patients when compared with the general population raises the possibility that the $\mathrm{GrH}$ and $\mathrm{HH}$ have the same or a similar trigger as in T1DM or MS.

It is of interest that the patterns of MOB between patients with $\mathrm{GrH}$ or $\mathrm{HH}$ differ. This may be due to a different type of autoimmune etiology despite a common trigger. The finding of a different MOB in patients with a very high titer of TPO is similar to findings reported in T1DM patients with high or multiple titers of anti- $\beta$-cell antibodies (27).

Seasonal factors, other than viral epidemics, which could be implicated are u.v. radiation and vitamin D (28), a deficiency of which is suspected to relate with the 

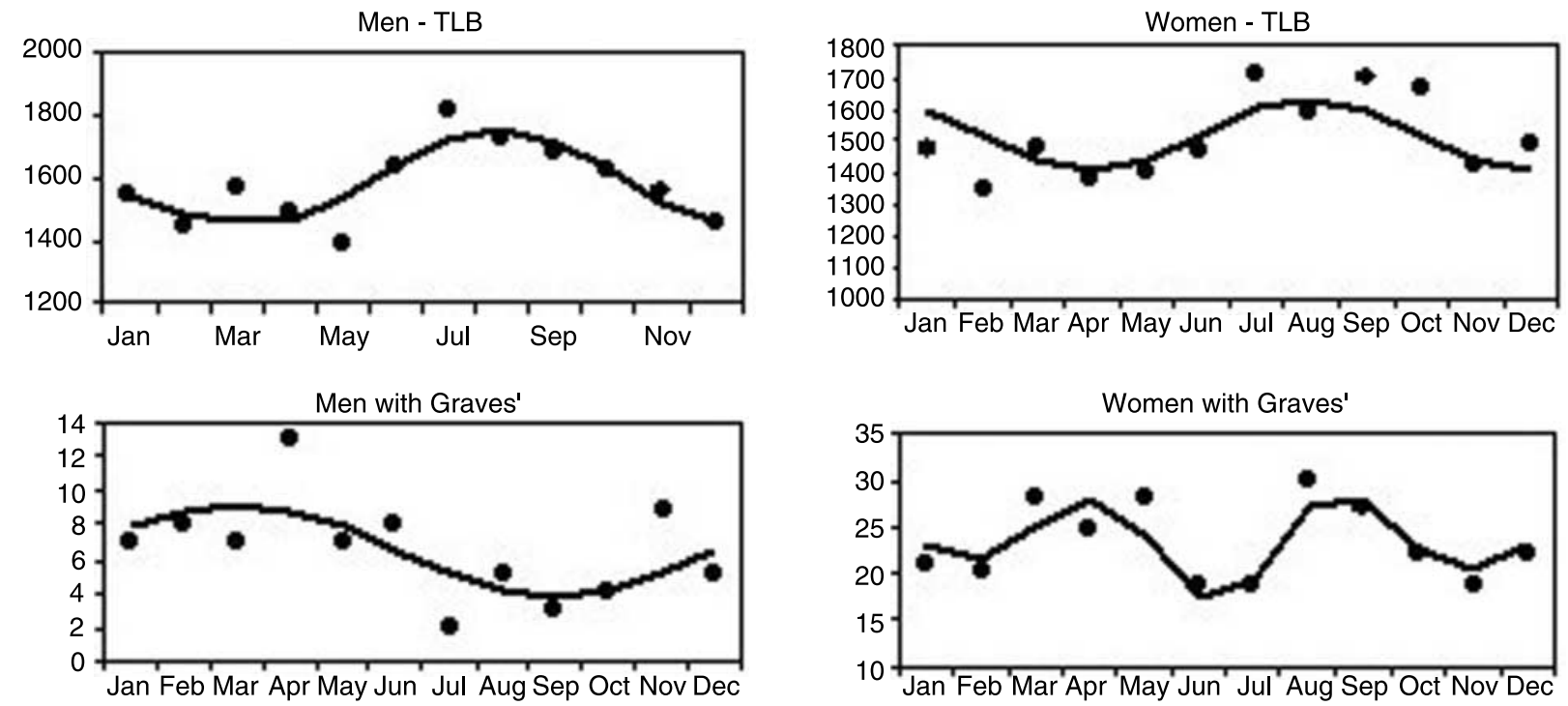

Figure 1 Comparison of month of birth distribution between patients with Graves' disease and the general population. TLB, total live births.

etiology of autoimmune diseases (29). Although Greece is a sunny country, a recent study has showed that a substantial percentage of the population suffers from vitamin D deficiency, particularly during winter (30).

It must be remembered that genetic and environmental factors have been shown to play a key role in the development of these diseases. It is likely that a genetic predisposition is necessary for the development of AITD and a seasonal viral infection acting as a sole

$$
\text { Men - TLB }
$$

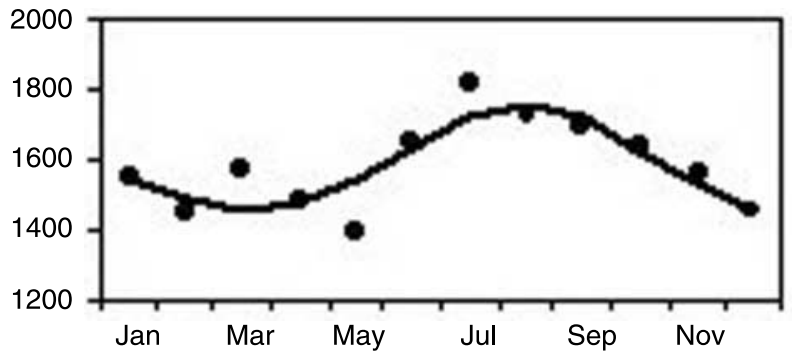

Men with Hashimoto's

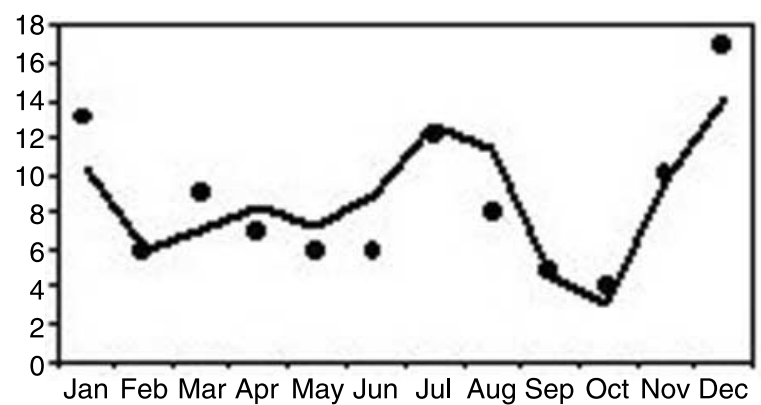

environmental pathogen or synergistically with other pathogens has a predominant role in controlling whether a genetically predisposed individual progresses to clinically overt disease. Other environmental factors such as iodine intake or smoking may act as triggers leading to the conversion of the subclinical to clinical disease.

Most studies of biological rhythms rely on two types of time series analytical approaches. One approach involves the fit of time series data by a mathematical

Women - TLB

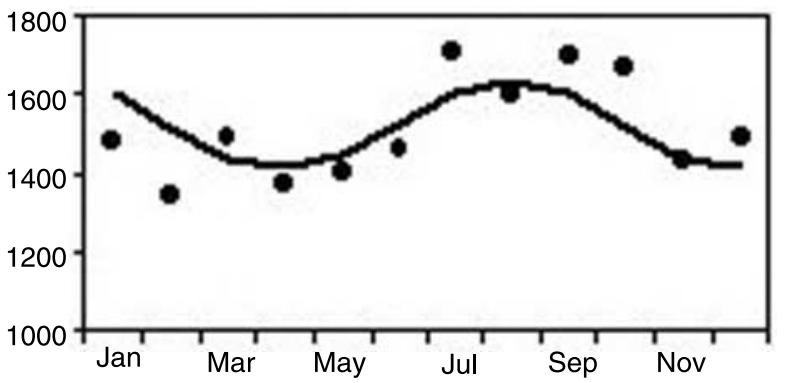

Women with Hashimoto's

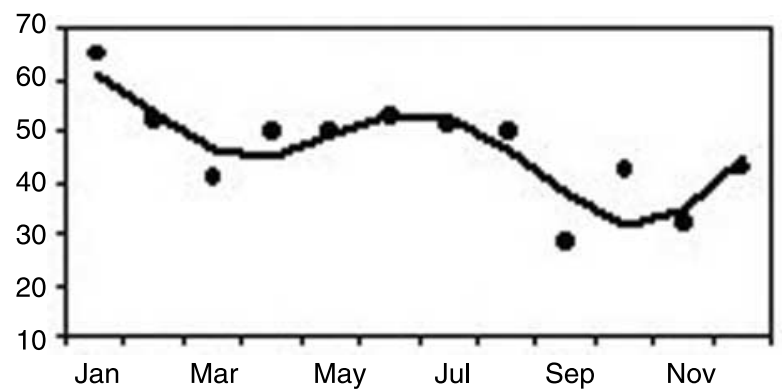

Figure 2 Comparison of month of birth distribution between patients with Hashimoto's thyroiditis and the general population. TLB, total live births. 
model (e.g., cosine function; (24)) with a predetermined period. The other approach involves subjecting the data to spectral analysis to ascertain information on the different ranges of cycles in the data. Epidemiological studies on yearly MOB distribution used the Poisson regression (31) or the Walter and Elwood test (32) methods, which are of limited use for small populations (33-37). The advantage of the cosinor analysis is that in addition to statistical significance it provides parameters regarding the rhythm $(36,37)$. Therefore, we analyzed the data by using cosinor analysis (24).

In conclusion, the different MOB seasonality in both $\mathrm{GrH}$ and $\mathrm{HH}$ point towards a similar, perhaps even common etiology with autoimmune diabetes and MS (38), namely a seasonal viral infection as the initial trigger in the perinatal period, the clinical disease resulting from further specific damage over time.

\section{References}

1 Prummel MF, Strieder T \& Wiersinga WM. The environment and autoimmune thyroid diseases. European Journal of Endocrinology $2004150605-618$.

2 Jacobson DL, Gange SJ, Rose NR \& Graham NM. Epidemiology and estimated population burden of selected autoimmune diseases in the United States. Clinical Immunology and Immunopathology 1997 $84223-243$.

3 Brix TH, Kyvik KO, Christensen K \& Hegedus L. Evidence for a major role of heredity in Graves' disease: a population-based study of two Danish twin cohorts. Journal of Clinical Endocrinology and Metabolism 200186 930-934.

4 Wheetman A. Chronic autoimmune thyroiditis. In Werner \& Ingbar: The Thyroid a Fundamental and Clinical Text, edn 9, p 703. Eds LE Braverman \& RD Utiger, New York: Lippincot Williams, 2005.

5 Floret D, Rosenberg D, Hage GN \& Monnet P. Hyperthyroidism, diabetes mellitus and the congenital rubella syndrome. Acta Paediatrica Scandinavica 198069 259-261.

6 Cabrera-Rode E, Sarmiento L, Tiberti C, Molina G, Barrios J, Hernández D, Díaz-Horta O \& Di Mario U. Type 1 diabetes islet associated antibodies in subjects infected by echovirus 16 . Diabetologia 200346 1348-1353.

7 Dahlquist G, Ivarsson S, Lindberg B \& Forsgren M. Maternal enteroviral infection during pregnancy is a risk factor for childhood IDDM. A population-based case-control study. Diabetes 199544 408-413.

8 Hiltunen M, Hyoty H, Knip M, Ilonen J, Reijonen H, Vahasalo P, Roivainen M, Lonnrot M, Leinikki P. Hovi T \& Akerblom HK. Islet cell antibody seroconversion in children is temporally associated with enterovirus infections. Childhood Diabetes in Finland (DiMe) Study Group. Journal of Infectious Diseases 1997175 554-560.

9 Lonnrot M, Korpela K, Knip M, Ilonen J, Simell O, Korhonen S, Savola K, Muona P, Simell T, Koskela P \& Hyoty H. Enterovirus infection as a risk factor for beta-cell autoimmunity in a prospectively observed birth cohort: the Finnish Diabetes Prediction and Prevention Study. Diabetes 200049 1314-1318.

10 Lonnrot M, Salminen K, Knip M, Savola K, Kulmala P, Leinikki P, Hyypia T, Akerblom HK \& Hyoty H. Enterovirus RNA in serum is a risk factor for beta-cell autoimmunity and clinical type 1 diabetes: a prospective study. Childhood Diabetes in Finland (DiMe) Study Group. Journal of Medical Virology 200061 214-220.

11 Hyoty H \& Taylor KW. The role of viruses in human diabetes. Diabetologia 200245 1353-1361.
12 Berti R \& Jacobson S. Role of viral infection in the aetiology of multiple sclerosis. Status of current knowledge and therapeutic implications. Central Nervous System Drugs 199912 1-7.

13 Lam-Tse WK, Batstra MR, Koeleman BPC, Roep BO, Bruining GJ, Aanstoot HJ \& Drexhage HA. The association between autoimmune thyroiditis, autoimmune gastritis and Type 1 diabetes. Pediatric Endocrinology Reviews 20031 22-37.

14 Sloka JS, Philips PW, Stefanelli M \& Joyce C. Co-occurrence of autoimmune thyroid disease in a multiple sclerosis cohort. Journal of Autoimmune Diseases 200529.

15 Lévy-Marchal C, Patterson C \& Green A. Variation by age group and seasonality at diagnosis of childhood IDDM in Europe. The EURODIAB ACE Study Group. Diabetologia 1995 38 823-830.

16 Laron Z. Interplay between heredity and environment in the recent explosion of type 1 childhood diabetes (DM). American Journal of Medical Genetics 2002115 4-7.

17 Phillips DIW, Barker DJP \& Morris JA. Seasonality of thyrotoxicosis. Journal of Epidemiology and Community Health 198539 $72-74$.

18 Ford HC, Johnson LA, Feek CM \& Newton JD. Iodine intake and the seasonal incidence of iodine incidence of thyrotoxicosis in New Zealand. Clinical Endocrinology 199134 179-181.

19 Westphal SA. Seasonal variation in the diagnosis of Graves' disease. Clinical Endocrinology 199441 27-30.

20 Ford HC. Seasonality of thyrotoxicosis in Wellington. New Zealand Medical Journal $198810172-73$.

21 Rothwell PM, Staines A, Smail P, Wadsworth E \& McKinney P. Seasonality of birth in childhood diabetes in Britain. BMJ 1996 312 1456-1457.

22 Laron Z. Childhood diabetes towards the 21st century. Journal of Pediatric Endocrinology and Metabolism 199811 387-402.

23 Songini M, Casu A, Ashkenazi I \& Laron Z. Seasonality of birth in children ( $0-14$ years) and young adults (0-29 years) with type 1 diabetes mellitus in Sardinia differs from that in the general population. The Sardinian Collaborative Group for Epidemiology of IDDM. Journal of Pediatric Endocrinology and Metabolism 200114 781-783.

24 Bingham C, Arbogast B, Guillaume GC, Lee JK \& Halberg F. Inferential statistical methods for estimating and comparing cosinor parameters. Chronobiologia 19829 397-439.

25 Laron Z, Rotstein A, Kahana E, Morrosu MG, Murray J, Monarch E \& Lewy H. Multiple sclerosis and celiac disease patients similar to childhood Type 1 diabetes have an abnormal seasonality of birth (Abstract \#O-8). 31st Annual Meeting of the International Society for Pediatric and Adolescent Diabetes (ISPAD), Krakow, Poland. Pediatric Diabetes 20056 (Suppl 3) 12.

26 Weetman AP. The thyroid and autoimmunity in children and adolescents. In Diseases of the Thyroid in Childhood and Adolescence, pp 104-117. Eds GE Krassas, SA Rivkees \& W Kiess, Karger: Basel, 2007.

27 Laron Z, Hampe C, Kordonouri O, Haberland H, Landin-Olsson M, Torn C \& Lewy H. Diabetic children with several or high GAD65 antibodies have a different seasonality of month of birth than no or low antibody populations (Abstract \#016). 32nd Annual Meeting of the International Society for Pediatric and Adolescent Diabetes (ISPAD), Cambridge, UK. Pediatric Diabetes 20067 (Suppl 5) 63.

28 Shehadeh N, Shamis I \& Laron Z. Seasonal variation of IDDM in Israel: the role of vitamin D. Diabetes Nutrition and Metabolism 199719 39-40.

29 Ponsonby AL, Lucas RM \& van der Mei IA. UVR, vitamin D and three autoimmune diseases-multiple sclerosis, type 1 diabetes, rheumatoid arthritis. Photochemistry and Photobiology $2005 \mathbf{8 1}$ 1267-1275.

30 Lapatsanis D, Moulas A, Cholevas V, Soukakos P, Papadopoulou ZL \& Challa A. Vitamin D: a necessity for children and adolescents in Greece. Calcified Tissue International 200577 348-355.

31 Molina EC. Poisson's Exponential Binomial Limit Princeton: Van Nostrand, 1942. 
32 Walter SD \& Elwood JM. A test for seasonality of events with a variable population at risk. British Journal of Preventive and Social Medicine 197529 18-21.

33 de Prins J \& Hecquet B. Data processing in chronobiology studies. In Biological Rhythms in Clinical and Laboratory Medicine, pp 90-113. Eds Y Touitou \& E House, Berlin-Heidelberg: Springer-Verlag, 1992.

34 St Leger AS. Comparison of two tests for seasonality in epidemiological data. Applied Statistics 197625 280-286.

35 Karvonen M. Seasonality in the clinical onset of insulin dependent diabetes mellitus in Finnish children. Childhood Diabetes in Finland (DiMe) Study Group. American Journal of Epidemiology $1996143167-176$.
36 Roger JH. A significance test for cyclic trends in incidence data. Biometrika 197764 152-155.

37 McKinney PA. On behalf of the EURODIAB Seasonality of Birth Group. Europe and Diabetes. Seasonality of birth in patients with childhood Type I diabetes in 19 European regions. Diabetologia 200144 (Suppl 3) B67-B74.

38 Hafler DA. Multiple sclerosis. Journal of Clinical Investigation 2004 $113788-794$.

Received 11 January 2007

Accepted 20 March 2007 